\title{
Comparison of the neuroprotective effects of the newly developed oximes (K027, K048) with trimedoxime in tabun-poisoned rats
}

\author{
Jiří Kassa, Gabriela Kunešová \\ Department of Toxicology, Faculty of Military Health Sciences, University of Defence, Hradec Králové, Czech \\ Republic
}

Received $24^{\text {th }}$ February 2006.

Revised $18^{\text {th }}$ April 2006.

Published online $30^{\text {th }}$ May 2006.

\begin{abstract}
Summary
Tabun (O-ethyl-N,N-dimethyl phosphoramidocyanidate) is one of the highly toxic organophosphorus compounds misused as chemical warfare agents for military as well as terroristic purposes. It differs from other highly toxic organophosphates in its chemical structure and by the fact that the commonly used antidotes (atropine in combination with an oxime) are not able to sufficiently eliminate its acute toxic effects.

The neuroprotective effects of the newly developed oximes (K027, K048) or trimedoxime in combination with atropine (atropine, K027/atropine, K048/atropine and trimedoxime/atropine mixtures) on rats poisoned with tabun at a lethal dose $\left(270 \mu \mathrm{g} / \mathrm{kg}\right.$ i.m.; $120 \%$ of $\mathrm{LD}_{50}$ value $)$ were studied. The tabun-induced neurotoxicity was monitored using a functional observational battery and an automaticmeasurement of motor activity. The neurotoxicity of tabun was monitored at 24 hours and 7 days following tabun challenge. The results indicate that atropine alone is not able to protect rats from the lethal effects of tabun. Five non-treated tabun-poisoned rats and five tabun-poisoned rat treated with atropine alone died within 24 hours. On the other hand, atropine combined with all tested oximes allows most tabun-poisoned rats to survive within 7 days following tabun challenge. All three oximes tested combined with atropine seem to be sufficiently effective antidotes for a decrease in tabun-induced neurotoxicity in the case of lethal poisonings, although they are not able to eliminate tabun-induced neurotoxicity completely. Due to their neuroprotective effects, all the tested oximes appear to be more suitable oximes for the antidotal treatment of acute tabun exposure than the currently used oximes (pralidoxime, obidoxime, HI-6).
\end{abstract}

Keywords: neuroprotective - neurotoxicity - oxime - rat - tabun

Jiří Kassa, P.O. Box 35/T, Faculty of Military Health Sciences, 50001 Hradec Králové, Czech Republic

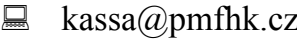
용 +420973251500
冝 $\quad+420495518094$

\section{INTRODUCTION}

Despite the entry into force in April 1997 of the Chemical Weapons Convention forbidding the production, storage and use of chemical warfare agents, the world has seen a rapid proliferation of such agents (Bajgar 2006). Highly toxic organophosphorus compounds, called nerve agents, are now considered to be the most dangerous chemical warfare agents. They pose potential 
neurotoxic threats to both military and civilian populations (as evidenced by terroristic attacks in Japan (Ohtomi et al. 1996)). Nerve agents exert their toxic effects by phosphonylation and subsequent inactivation of acetylcholinesteraserase (AChE, EC 3.1.1.7). The inactivation of this enzyme allows the accumulation of acetylcholine (ACh) in the synaptic terminals of the central and peripheral nervous systems with subsequent widespread overstimulation of the cholinergic receptors (Marrs 1993, Taylor 1996).

The current antidotal treatment of organophosphorus agent-induced acute poisoning usually consists of anticholinergic drugs to antagonize the effects of acetylcholine excess at cholinergic receptor sites, and oximes to reactivate organophosphorus agent-inhibited AChE. In addition, anticonvulsive drugs, preferably benzodiazepines, are currently used in antidotal treatment to control centrally mediated seizures and tonic-clonic convulsions (Kassa 2002, Taylor 1996). Unfortunately, some organophosphorus compounds have been found to be resistant to standard antidotal treatment. One of the most resistant organophosphorus compounds is tabun (ethyl-N,N-dimethyl phosphoramidocyanidate). Its deleterious effects are extraordinarily difficult to counteract because of the existence of a free electron pair located on amidic nitrogen that makes a nucleophilic attack of oximes almost impossible (Cabal and Bajgar 1999, Eto 1976).

Tabun is able to cause centrally mediated seizure activity that can rapidly progress to status epilepticus and contribute to profound brain damage. The exposure of experimental animals to tabun in convulsion-induced doses may result in irreversible lesions in the central nervous system that can be manifested as behavioral effects in convulsing survivors (Jokanovic 1993). Therefore, the ability of antidotes to counteract the acute neurotoxic effects of tabun and prevent tabun- poisoned organisms from irreversible lesions in the central nervous system is very important for the successful antidotal treatment of acute tabun poisonings. The oximes are more potent in the peripheral compartment than in the central compartment due to their poor penetration into the central nervous system. Nevertheless, there are published results demonstrating the penetration of oximes into the central nervous system and subsequent reactivation of nerve agent-inhibited AChE in the brain (Cassel et al. 1997, Sakurada et al. 2003). Although the rate of reactivation of nerve agent-inhibited AChE in the brain is lower compared to the peripheral compartment, it is very important for the survival of nerve agent-poisoned organisms (Marrs 1993, Kassa 2002).

As the ability of currently used monopyridinium (e.g. pralidoxime) and bispyridinium oximes (e.g. obidoxime, HI-6) to eliminate toxic effects of tabun is generally rather low (Kassa et al. 2005), the replacement of the commonly used oximes (pralidoxime, obidoxime) as well as $\mathrm{H}$ oximes (the oxime HI-6) with a more effective oxime has been a long-standing goal for the treatment of tabun poisoning (Dohnal et al. 2005). New asymmetric bispyridinium oximes, called $\quad \mathrm{K} 027 \quad$ [1-(4-hydroxyiminomethyl pyridinium)-3-(4-carbamoylpyridinium) propane dibromide] and K048 [1-(4-hydroxyiminomethyl pyridinium)-3-(4-carbamoylpyridinium) butane dibromide] were synthesized at our Department of Toxicology (Kuca et al. 2003a, b) (Figure 1) to improve the efficacy of antidotal treatment in reactivating tabun-inhibited $\mathrm{AChE}$ and eliminating the acute lethal toxic effects induced by tabun. In addition, another oxime called trimedoxime (1,3bis (4-hydroxyiminomethyl pyridinium) propane dibromide) (Figure 1) (Poziomek et al. 1958) was chosen for the testing of its neuroprotective efficacy against tabun.<smiles>CC[n+]1ccc(C(N)=O)cc1</smiles>

K027<smiles>NC(=O)c1cc[n+](CCCC[n+]2ccc(/C=N/O)cc2)cc1</smiles>

K048<smiles>CC[n+]1ccc(/C=N/O)cc1</smiles>

Trimedoxime

Fig. 1. Chemical structure of the oximes studied

The aim of this study was to evaluate the neuroprotective effects of a currently available oxime trimedoxime and newly developed oximes (K027, K049) in combination with an 
anticholinergic drug, atropine, in tabun-poisoned rats. The tabun-induced neurotoxic signs were determined using a functional observational battery: a non-invasive and relatively sensitive type of neurological examination in that a wide range of neurobiological functions including measurements of sensory, motor and autonomic nervous functions are assessed.

\section{MATERIAL AND METHODS}

Male albino Wistar rats weighing 180-220g were purchased from Konárovice (Czech Republic). They were kept in an air-conditioned room and allowed access to standard food and tap water ad libitum. The rats were divided into groups of eight animals $(\mathrm{N}=8)$. Handling of the experimental animals was done under the supervision of the Ethics Committee of the Faculty of Military Health Sciences in Hradec Kralove (Czech Republic).

Tabun was obtained from the Military Technical Institute in Brno (Czech Republic) and was $95 \%$ pure. Its purity was assayed by acidimetric titration. Trimedoxime and the newly developed oximes (K027, K048) of 98.5\% purity were synthesized at the Department of Toxicology of the Faculty of Military Health Sciences in Hradec Kralove (Czech Republic). Their purity was analysed using HPLC. All other drugs and chemicals of analytical grade were obtained commercially and used without further purification. All substances were administered intramuscularly (i.m.) at a volume of $1 \mathrm{~mL} / \mathrm{kg}$ body weight (b.w.).

Tabun was administered at a lethal dose (270 $\mu \mathrm{g} / \mathrm{kg}$ b.w. $-120 \% \mathrm{LD}_{50}$ ). One minute following tabun challenge, the rats were treated with atropine (21 $\mathrm{mg} / \mathrm{kg}$ b.w.) alone or in combination with trimedoxime, $\mathrm{K} 027$ or $\mathrm{K} 048$ at equimolar doses corresponding to $10 \mu \mathrm{mol} / \mathrm{kg}$ b.w. The control rats were administered with saline instead of tabun and antidotes at the same volume. The neurotoxicity of tabun was monitored using the functional observational battery at 24 hours and 7 days following tabun poisoning. The evaluated markers of tabun-induced neurotoxicity in experimental animals were compared with the parameters obtained from the control rats.

The functional observational battery consists of 47 measurements of sensory, motor and autonomic nervous functions. Some of them are scored, the others are measured in absolute units (Frantik and Hornychova 1995, Hornychova and 1995, Moser and 1997) (Table 1). The first evaluation was obtained when tabun-poisoned or control rats were in the home cage. The observer evaluated each animal's posture, palpebral closure and involuntary motor movements. Then, each rat was removed from the home cage and briefly held in the hand.
The exploratory activity, piloerection and other skin abnormalities were noted, and salivation and nose secretion were also registered and scored.

Then, the rats were placed on a flat surface which served as an open field. A timer was started for three minutes during which the frequency of rearing responses was recorded. At the same time, gait characteristics were noted and ranked, and arousal, stereotypy, bizarre behaviors and abnormal posture were evaluated. At the end of the third minute, the number of fecal boluses and urine pools on the absorbent pad was registered. A reflex testing consisting of recording each rat's response to the frontal approach of the blunt end of a pen, a touch of the pen to the posterior flank and an auditory clic stimulus was also used. The responsiveness to a pinch on the tail and the ability of pupils to constrict in response to light were then assessed. These measures were followed by a test for the aerial righting reflex and by the measurements of forelimb and hindlimb grip strength, body weight, rectal temperature and finall hindlimb landing foot splay. The whole battery of tests required approximately 6-8 minutes per rat. The observer of the behaviour did not know about the design of the experiments.

Motor activity data were collected shortly after the end of the functional observational battery, using an apparatus for testing of the spontaneous motor activity of laboratory animals (constructed in the Faculty of Military Health Sciences, Hradec Kralove, Czech Republic). The animals were placed for a short period (10 minutes) in the measuring cage and their movements (total, horizontal and vertical activity) were recorded.

Data collected with the functional observational battery and motor activity assessment, include categorial, ordinal and continuous values. Their statistical analyses were performed on a PC with a special interactive programme NTX (Frantik and Hornychova 1995). The categorial and ordinal values were formulated as contingency tables and judged consecutively by the Chi-squared test of homogeneity, the Concordance-Discordance test and the KruskalWallis test, respectively. The continual data were assessed by successive statistical tests: the CI for Delta, the Barlett test for Equality of Variance, the Williams test and the Test for Distribution Functions (Roth et al. 1962). The differences were considered significant at the level 2alpha $=0.05$.

\section{RESULTS}

Only three non-treated tabun-poisoned rats survived till the end of the experiment ( 7 days following the intoxication); five non-treated tabunpoisoned rats died within 2 hours following tabun 
Table 1. Functional observational battery (FOB)

\begin{tabular}{|c|c|c|c|c|c|c|c|c|}
\hline \multirow{2}{*}{ MARKER } & \multicolumn{8}{|c|}{ Scored values only } \\
\hline & -2 & -1 & 0 & 1 & 2 & 3 & 4 & 5 \\
\hline POSTURE & & & & $\begin{array}{l}\text { sitting or } \\
\text { standing }\end{array}$ & rearing & asleep & flattened & lying on side \\
\hline CATCH DIFFICULTY & & & & passive & normal & defense & flight & escape \\
\hline EASE OF HANDLING & & & & very easy & easy & moderately difficult & difficult & \\
\hline MUSCULAR TONUS & atonia & hypotonia & normal & hypertonia & rigidity & fasciculations & & \\
\hline LACRIMATION & & & none & slight & severe & crusta & coloured crusta & \\
\hline PALPEBRAL CLOSURE & & & & open & $\begin{array}{l}\text { slightly } \\
\text { drooping }\end{array}$ & half-way drooping & completely shut & ptosis \\
\hline $\begin{array}{l}\text { ENDO- } \\
\text { EXOPHTHALMUS }\end{array}$ & & endo & normal & exo & & & & \\
\hline PILOERECTION & & & no & yes & & & & \\
\hline SKIN ABNORMALITIES & & & normal & pale & erythema & cyanosis & pigmented & cold \\
\hline SALIVATION & & & none & sllight & severe & & & \\
\hline NOSE SECRETION & & & none & $\begin{array}{l}\text { slight } \\
\text { repetitive }\end{array}$ & severe & coloured & & \\
\hline CLONIC MOVEMENTS & & & normal & $\begin{array}{l}\text { movements of } \\
\text { mouth and } \\
\text { jaws }\end{array}$ & $\begin{array}{l}\text { non-rhythmic } \\
\text { quivers }\end{array}$ & mild tremors & severe tremors & myoclonic jerks \\
\hline TONIC MOVEMENTS & & & normal & $\begin{array}{l}\text { contraction of } \\
\text { extensors }\end{array}$ & opisthotonus & emprostho- tonus & explosive jumps & tonic convulsions \\
\hline GAIT & & & normal & ataxia & $\begin{array}{l}\text { overcompen- } \\
\text { sation of } \\
\text { hindlimb } \\
\text { movements }\end{array}$ & $\begin{array}{l}\text { feet point outwards } \\
\text { from body }\end{array}$ & forelimbs are extended & walks on tiptoes \\
\hline GAIT SCORE & & & & normal & $\begin{array}{l}\text { slightly } \\
\text { impaired }\end{array}$ & somewhat impaired & totally impaired & \\
\hline
\end{tabular}


MOBILITY SCORE

AROUSAL (level of unprovoked activity)

TENSION

STEREOTYPY

BIZARRE BEHAVIOR

APPROACH RESPONSE

TOUCH RESPONSE

CLICK RESPONSE

TAIL - PINCH

RESPONSE

PUPIL SIZE

PUPIL RESPONSE

RIGHTING REFLEX

\begin{tabular}{|c|c|c|c|c|c|c|}
\hline & & normal & $\begin{array}{l}\text { slightly } \\
\text { impaired }\end{array}$ & somewhat impaired & totally impaired & \\
\hline & & very low & sporadic & reduced & normal & enhanced \\
\hline & none & partial (ears) & stupor & & & \\
\hline & none & head weaving & body weaving & grooming & circling & others \\
\hline & none & head & body & self-mutilation & abnormal movements & others \\
\hline & & no reaction & normal & slow reaction & energetic reaction & exaggerated reaction \\
\hline & & no reaction & normal & slow reaction & energetic reaction & exaggerated reaction \\
\hline & & no reaction & normal & slow reaction & energetic reaction & exaggerated reaction \\
\hline & & no reaction & normal & slow reaction & energetic reaction & exaggerated reaction \\
\hline \multirow{3}{*}{ miosis } & normal & mydriasis & & & & \\
\hline & no reaction & $\begin{array}{l}\text { normal } \\
\text { reaction }\end{array}$ & & & & \\
\hline & & normal & $\begin{array}{l}\text { slightly } \\
\text { uncoordin. }\end{array}$ & lands on side & lands on back & \\
\hline
\end{tabular}


Table 2. The values of tabun-induced neurotoxic markers measured at 24 hours following tabun challenge by the functional observational battery (No 1-11, 14-36 - scored values, No 12-13, 37-47 - values in absolute units).

\begin{tabular}{|c|c|c|c|c|c|c|c|c|c|c|c|c|c|}
\hline \multicolumn{2}{|c|}{24 hours } & \multicolumn{2}{|c|}{ Controls } & \multicolumn{2}{|c|}{$\mathrm{A}+\mathrm{K} 027$} & \multicolumn{2}{|c|}{$\mathrm{A}+$ Trimedoxime } & \multicolumn{2}{|c|}{$\mathrm{A}+\mathrm{K} 048$} & \multicolumn{2}{|c|}{ Atropine } & \multicolumn{2}{|c|}{ Tabun } \\
\hline No & Marker & $x / M$ & $-/+s$ & $x / M$ & $-/+s$ & $x / M$ & $-/+s$ & $x / M$ & $-/+s$ & $x / M$ & $-/+s$ & $x / M$ & $\begin{array}{c}-/+ \\
\boldsymbol{S} \\
\end{array}$ \\
\hline 1 & posture & 1.00 & & 3.00 & & 3.00 & & 3.00 & & $7.00 *$ & & $7.00 *$ & \\
\hline 2 & catch difficulty & 2.00 & & $1.00 *$ & & $1.00 *$ & & $1.00 *$ & & $1.00 *$ & & $1.00 *$ & \\
\hline 3 & ease of handling & 2.00 & & $1.00 *$ & & $1.00 *$ & & $1.00 *$ & & $1.00 *$ & & $1.00 *$ & \\
\hline 4 & muscular tonus & 0.00 & & $'-1.00 *$ & & $-2.00 \%$ & & $'-2.00 *$ & & $'-2.00 *$ & & $'-2.00 \%$ & \\
\hline 5 & lacrimation & 0.00 & & 0.00 & & 0.00 & & 0.00 & & $4.00 *$ & & $4.00 *$ & \\
\hline 6 & palpebral closure & 1.00 & & 1.00 & & 1.00 & & 1.00 & & $5.00 *$ & & $5.00 *$ & \\
\hline 7 & endo/exophtalmus & 0.00 & & 0.00 & & 0.00 & & 0.00 & & $'-1.00 *$ & & $'-1.00 *$ & \\
\hline 8 & fur abnormalities & 0.00 & & 0.00 & & 0.00 & & 0.00 & & 7.00* & & $7.00 *$ & \\
\hline 9 & skin abnormalities & 0.00 & & 0.00 & & 0.00 & & 0.00 & & $3.00 *$ & & $3.00 *$ & \\
\hline 10 & salivation & 0.00 & & 0.00 & & 0.00 & & 0.00 & & $2.00 *$ & & $2.00 *$ & \\
\hline 11 & nose secretion & 0.00 & & $3.00 *$ & & 0.00 & & $3.00 *$ & & $3.00 *$ & & $3.00 *$ & \\
\hline 12 & rearing & 15.50 & 4.540 & $0.830^{*}$ & 0.980 & $5.00 *$ & 7.640 & $4.670^{*}$ & 3.780 & $1.67^{*}$ & 1.530 & $4.00 *$ & 0.00 \\
\hline 13 & urination & 1.880 & 3.720 & 3.500 & 6.120 & 3.00 & 5.130 & 0.00 & 0.00 & 11.330 & 16.170 & 3.00 & 0.00 \\
\hline 14 & defecation & 0.00 & & 0.00 & & 0.00 & & 0.00 & & 0.00 & & 0.00 & \\
\hline 15 & hyperkinesis & 0.00 & & 0.00 & & 0.00 & & 0.00 & & $7.00 *$ & & $7.00 *$ & \\
\hline 16 & tremors & 0.00 & & 0.00 & & 0.00 & & 0.00 & & $5.00^{*}$ & & $5.00 *$ & \\
\hline 17 & clonic movements & 0.00 & & 0.00 & & 0.00 & & 2.00 & & $2.00 *$ & & $2.00 *$ & \\
\hline 18 & tonic movements & 0,00 & & 0.00 & & 0.00 & & 0.00 & & $5.00^{*}$ & & $5.00 *$ & \\
\hline 19 & gait & 0.00 & & 1.00 & & 1.00 & & 7.00 & & $7.00 *$ & & $7.00 *$ & \\
\hline 20 & ataxia & 0.00 & & $1.00 *$ & & $1.00^{*}$ & & $2.00 *$ & & $2.00^{*}$ & & $2.00 *$ & \\
\hline 21 & gait score & 0.00 & & 0.00 & & 0.00 & & 2.00 & & $2.00 *$ & & $2.00 *$ & \\
\hline 22 & mobility score & 1.00 & & 3.00 & & 2.00 & & $4.00 *$ & & $4.00 *$ & & $4.00 *$ & \\
\hline 23 & arousal (GSC) & 1.00 & & $2.00 *$ & & $2.00 *$ & & $4.00 *$ & & $4.00 *$ & & $4.00 *$ & \\
\hline
\end{tabular}




\begin{tabular}{|c|c|c|c|c|c|c|c|c|c|c|c|c|c|}
\hline 24 & activity & 4.00 & & $1.00 *$ & & 1.00 & & 1.00 & & $1.00 *$ & & $1.00 *$ & \\
\hline 25 & tension & 0.00 & & 0.00 & & 0.00 & & 0.00 & & 0.00 & & 0.00 & \\
\hline 26 & vocalisation & 0.00 & & 0.00 & & 0.00 & & 0.00 & & 0.00 & & 0.00 & \\
\hline 27 & stereotypy & 0.00 & & 0.00 & & 0.00 & & 0.00 & & 0.00 & & 0.00 & \\
\hline 28 & bizzare behavior & 0.00 & & 0.00 & & 0.00 & & 0.00 & & 0.00 & & 0.00 & \\
\hline 29 & approach response & 2.00 & & $1.00 *$ & & $1.00 *$ & & $1.00 *$ & & $1.00 *$ & & $1.00 *$ & \\
\hline 30 & touch response & 2.00 & & $1.00 *$ & & $1.00 *$ & & $1.00 *$ & & $1.00 *$ & & $1.00 *$ & \\
\hline 31 & click response & 2.00 & & 3.00 & & $3.00 *$ & & $2.00 *$ & & $1.00 *$ & & $1.00 *$ & \\
\hline 32 & tail-pinch response & 2.00 & & 1.00 & & 2.00 & & $1,00 *$ & & $1.00 *$ & & $1.00 *$ & \\
\hline 33 & pupil size & 0.00 & & $-2.00 \%$ & & 2.00 & & $-2.00 \%$ & & $-2.00 \%$ & & $'-2.00 \%$ & \\
\hline 34 & pupil response & 1.00 & & $0.00 *$ & & $0.50 *$ & & $0.00 *$ & & $0.00 *$ & & $0.00 *$ & \\
\hline 35 & RRF & 1.00 & & 2.00 & & 1.00 & & 2.00 & & $7.00 *$ & & $7.00 *$ & \\
\hline 36 & RRV & 1.00 & & 1.00 & & 1.00 & & 1.00 & & $4.00 *$ & & $4.00 *$ & \\
\hline 37 & $\begin{array}{l}\text { landing foot splay }(\mathrm{mm}) \\
\text { forelimb grip strength }\end{array}$ & 107.380 & 21.270 & 67.380 & 45.050 & $71.19 *$ & 29.620 & 64.50 & 42.010 & 29.250 & 41.280 & $9.63 *$ & 27.220 \\
\hline 38 & $\begin{array}{l}(\mathrm{kg}) \\
\text { hindlimb grip strength }\end{array}$ & 6.480 & 1.030 & $4.05 *$ & 0.480 & $4.71 *$ & 0.480 & $4.12 *$ & 1.290 & $4.10 *$ & 0.44 & $2.40 *$ & 0.00 \\
\hline 39 & $\begin{array}{l}(\mathrm{kg}) \\
\text { grip strength of all limbs }\end{array}$ & 1.190 & 0.16 & $0.50 * *$ & 0.15 & $0.56 *$ & 0.13 & $0.55 *$ & 0.29 & $0.47 *$ & 0.06 & $0.40 *$ & 0.00 \\
\hline 40 & $(\mathrm{~kg})$ & 19.880 & 3.820 & $10.470 *$ & 2.970 & $9.760 *$ & 4.630 & $10.67^{*}$ & 4.630 & $6.03 *$ & 0.31 & $12.80^{*}$ & 0.00 \\
\hline 41 & food receiving $(\%)$ & 100.00 & 0.00 & $18.50 *$ & 12.220 & $36.25^{*}$ & 16.420 & $23.13 *$ & 16.680 & $12.50 *$ & 23.150 & $0.63 *$ & 1.770 \\
\hline 42 & body weight (g) & 254.00 & 17.670 & 277.670 & 23.520 & 281.430 & 17.650 & $277.83 *$ & 14.150 & 232.670 & 22.480 & 265.00 & 0.00 \\
\hline 43 & body temperature $\left({ }^{\circ} \mathrm{C}\right)$ & 37.260 & 0.26 & $36.13 *$ & 0.35 & 36.960 & 0.37 & $36.68^{*}$ & 0.45 & $34.67^{*}$ & 0.40 & $36.10 *$ & 0.00 \\
\hline 44 & respiration & 0.00 & & 0.00 & & 0.00 & & 0.00 & & $'-2.00$ & & $'-2.00 *$ & \\
\hline 45 & vertical activity & 259.00 & 68.110 & $65.67 *$ & 45.460 & $33.00 *$ & 51.070 & $37.33 *$ & 53.460 & $8.00 *$ & 0.00 & 0.00 & 0.00 \\
\hline 46 & horizontal activity & 54.130 & 41.360 & 3.33* & 5.920 & $6.86 *$ & 18.140 & 3.00 & 5.200 & 2.00 & 0.00 & 0.00 & 0.00 \\
\hline 47 & total motor activity & 313.130 & 98.10 & $51.75 *$ & 53.740 & $34.88 *$ & 64.360 & $15.13 *$ & 37.360 & $1.25 *$ & 3.540 & 0.00 & 0.00 \\
\hline & & \multicolumn{2}{|c|}{$\mathrm{n}=8$} & \multicolumn{2}{|c|}{$\mathrm{n}=6$} & \multicolumn{2}{|c|}{$\mathrm{n}=7$} & \multicolumn{2}{|c|}{$\mathrm{n}=6$} & \multicolumn{2}{|c|}{$\mathrm{n}=3$} & \multicolumn{2}{|c|}{$\mathrm{n}=3$} \\
\hline
\end{tabular}

* statistically significant at $2 \alpha=0.05$ (comparison with the control values) 
Table 3 : The values of tabun-induced neurotoxic markers measured at $\mathbf{7}$ days following tabun challenge by the functional observational battery (No 1-11, 14-36 - scored values, No 12-13, 37-47 - values in absolute units).

\begin{tabular}{|c|c|c|c|c|c|c|c|c|c|c|c|c|c|}
\hline \multicolumn{2}{|c|}{7 days } & \multicolumn{2}{|l|}{ Controls } & \multicolumn{2}{|c|}{$\mathrm{A}+\mathrm{K} 027$} & \multicolumn{2}{|c|}{ A-Trimedoxime } & \multicolumn{2}{|c|}{$\mathrm{A}+\mathrm{K} 048$} & \multicolumn{2}{|l|}{ Atropine } & \multicolumn{2}{|l|}{ Tabun } \\
\hline No & $\begin{array}{l}\text { Marke } \\
r\end{array}$ & $x / M$ & $-/+s$ & $x / M$ & $-/+s$ & $x / M$ & $-/+s$ & $x / M$ & $-/+s$ & $x / M$ & $-/+s$ & $x / M$ & $-/+s$ \\
\hline 1 & posture & 1.00 & & 1.00 & & 3.00 & & $7.00 *$ & & $7.00 *$ & & $7.00 *$ & \\
\hline 2 & catch difficulty & 2.00 & & $2.00 *$ & & 2.00 & & $1.00 *$ & & $1.00 *$ & & $1.00 *$ & \\
\hline 3 & ease of handling & 2.00 & & 2.00 & & 2.00 & & $1.00 *$ & & $1.00 *$ & & $1.00 *$ & \\
\hline 5 & lacrimation & 0,00 & & 0.00 & & 0.00 & & 0.00 & & $4.00 *$ & & $4.00 *$ & \\
\hline 6 & palpebral closure & 1.00 & & 1.00 & & 1.00 & & 1.00 & & $5.00 *$ & & $5.00 *$ & \\
\hline 7 & endo/exophtalmus & 0.00 & & 0.00 & & 0.00 & & 0.00 & & $'-1.00 *$ & & $'-1.00 *$ & \\
\hline 8 & fur abnormalities & 0.00 & & 0.00 & & 0.00 & & 0.00 & & $7.00 *$ & & $7.00 *$ & \\
\hline 9 & skin abnormalities & 0.00 & & 0.00 & & 0.00 & & 0.00 & & $3.00 *$ & & $3.00 *$ & \\
\hline 10 & salivation & 0.00 & & 0.00 & & 0.00 & & 0.00 & & $2.00 *$ & & $2.00 *$ & \\
\hline 11 & nose secretion & 0.00 & & 0.00 & & 0.00 & & 0.00 & & $3.00 *$ & & $3.00 *$ & \\
\hline 13 & urination & 0.00 & & 0.00 & & 0.00 & & 0.00 & & 0.00 & & 0.00 & \\
\hline 14 & defecation & 0.00 & & 0.00 & & 0.00 & & 2,00 & & 0.00 & & 0,00 & \\
\hline 15 & CLO & 0.00 & & 0.00 & & $3.00 *$ & & 0.00 & & $7.00 *$ & & $7.00 *$ & \\
\hline 16 & TRE & 0.00 & & 0.00 & & $2.00 *$ & & 0.00 & & $5.00 *$ & & $5.00 *$ & \\
\hline 17 & clonic movements & 0.00 & & 0.00 & & 0.00 & & 0.00 & & $2.00 *$ & & $2.00 *$ & \\
\hline 18 & tonic movements & 0.00 & & 0.00 & & 0.00 & & 0.00 & & $5.00 *$ & & $5.00 *$ & \\
\hline 19 & gait & 0.00 & & 0.00 & & $1.00 *$ & & $7.00 *$ & & $7.00 *$ & & $7.00 *$ & \\
\hline 20 & ataxia & 0.00 & & 0.00 & & $1.00 *$ & & $2.00 *$ & & $2.00 *$ & & $2.00 *$ & \\
\hline $21 \mathrm{ss}$ & gait score & 0.00 & & 0.00 & & 0.00 & & 0.00 & & $2.00 *$ & & $2.00 *$ & \\
\hline 22 & mobility score & 1.00 & & 1.00 & & 1.00 & & 4.00 & & $4.00 \%$ & & $4.00 *$ & \\
\hline 23 & arousal (GSC) & 1.00 & & 1.00 & & 2.00 & & $4.00 *$ & & $4.00 *$ & & $4.00 *$ & \\
\hline 24 & $\mathrm{ACT}$ & 4,00 & & 1.00 & & 1.00 & & $1.00^{*}$ & & $1.00 *$ & & $1.00 *$ & \\
\hline
\end{tabular}




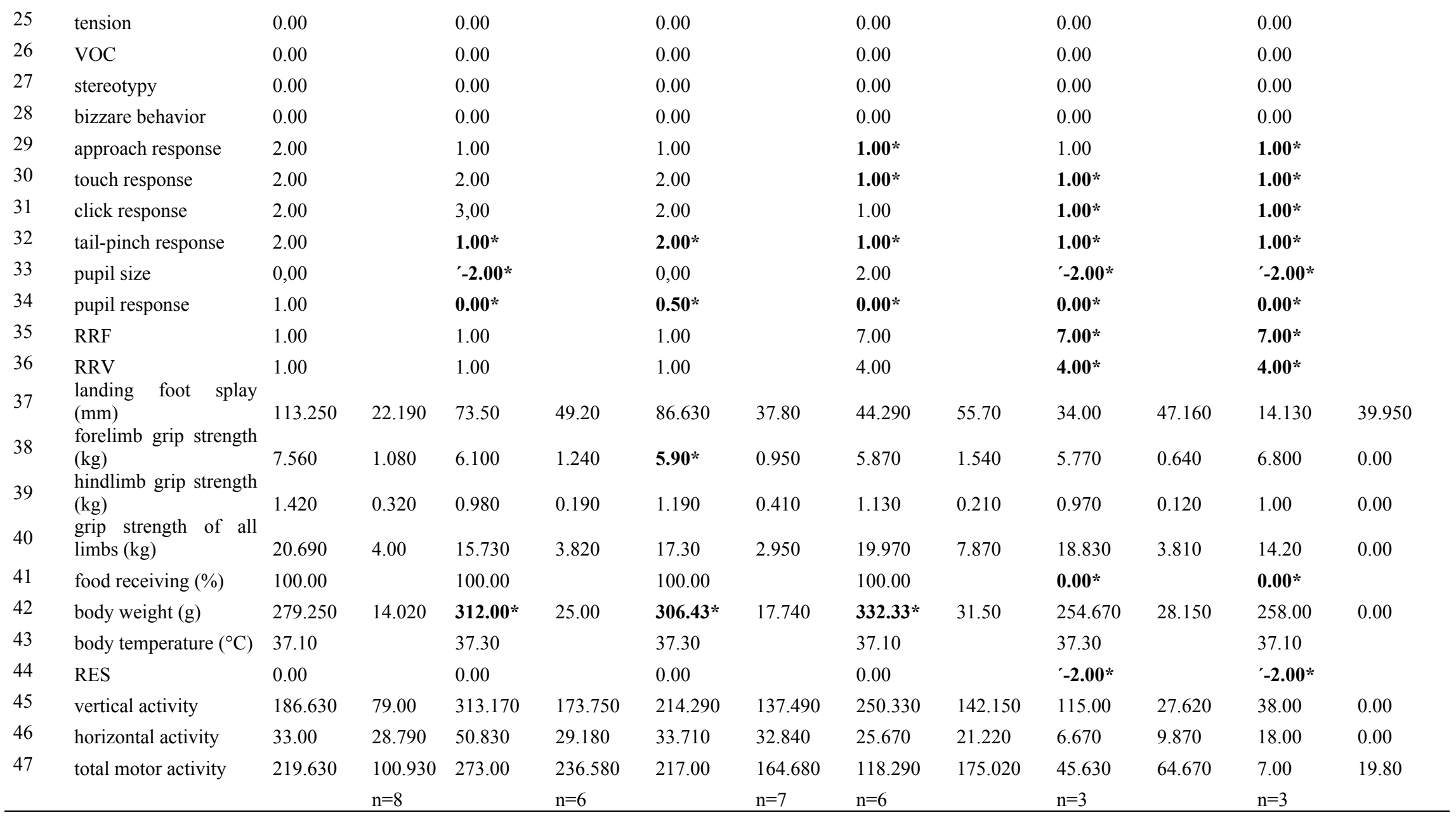

Symbols as in Table 2 
challenge. While most tabun-poisoned rats (six or seven) treated with atropine in combination with one of the tested oximes survived till the end of the experiment, only three tabun-poisoned rats treated with atropine alone survived and five tabunpoisoned rats treated with atropine alone died within 2 hours following tabun administration.

The results of the experiments relating to the measurement of tabun-induced neurotoxicity at $24 \mathrm{~h}$ and $7 \mathrm{~d}$ following tabun poisoning are summarized in Table 2 and 3. The observation of neurotoxic signs indicated that many functional disorders of poisoned organisms lasted at least 24 hours not only in the non-treated tabun-poisoned rats but also in tabun-poisoned rats treated with atropine alone.

Tabun caused passive behavior of rats during handling and catching, enophthalmus and an increase in lacrimation, salivation and nose secretion at $24 \mathrm{~h}$ following its administration. The exploratory activity was significantly decreased, gait and mobility were severely impaired and tonic convulsions were observed.

In addition, no reactions were observed during a reflex testing consisting of the recording of each rat's response to the frontal approach of the blunt end of a pen, a touch of the pen to the posterior flank and an auditory clic stimulus. No responsiveness to a pinch on the tail nor the ability of pupils to constrict in response to light was demonstrated. A significant decrease in the distance between hindpaws after a jump, forelimb and hindlimb grip strength, food receiving, body temperature and spontaneous horizontal as well as vertical motor activity were also observed at $24 \mathrm{~h}$ following tabun challenge (Tab. 2).

All three oximes tested in combination with atropine were able to eliminate some tabun-induced signs of neurotoxicity observed at 24 hours following tabun challenge with the exception of the passive behavior of rats during handling and catching, ataxia, a decrease in the ability of pupils to constrict in response to light, forelimb and hindlimb grip strength, food receiving and spontaneous horizontal as well as vertical motor activity (Tab. 2).

Practically all the signs of tabun-induced neurotoxicity in tabun-poisoned rats non-treated or treated with atropine alone were also observed at 7 days following tabun administration. While trimedoxime and $\mathrm{K} 027$ in combination with atropine were able to eliminate almost all signs of tabun-induced neurotoxicity, tabun-poisoned rats treated with $\mathrm{K} 048$ in combination with atropine showed passive behavior during handling and catching and the impairment of gait and mobility (Tab. 3).

\section{DISCUSSION}

In the case of the treatment of tabun-poisoned rats with atropine alone, the elimination of tabuninduced neurotoxic effects at $24 \mathrm{~h}$ as well as $7 \mathrm{~d}$ following soman challenge was not observed. Thus, atropine alone was not able to prevent tabuninduced seizures and subsequent neurotoxic effects following exposure to tabun at lethal and supralethal doses because it is considered to be a muscarinic blocker with a relatively low central antimuscarinic activity in comparison with other anticholinergic drugs such as benactyzine, biperiden and scopolamine (Kassa and Koupilová 2000, McDonough et al. 2000 ).

Therefore, the anticholinergic drugs such as atropine should be combined with a AChE reactivator for the antidotal treatment of tabun poisonings to improve its efficacy, although the central reactivating efficacy of oximes is lower compared to their peripheral reactivating efficacy due to their poor penetration into the central nervous system (Kassa 2002). Pralidoxime, a commonly available oxime for the treatment of poisonings with highly toxic organophosphates (Dawson 1994), seems to be practically ineffective in preventing tabun-induced neurotoxicity (Kassa and Krejcova 2003). Another currently used oxime (obidoxime) is able to partly eliminate tabuninduced acute neurotoxicity following i.m. administration of tabun at a lethal dose; nevertheless, its neuroprotective efficacy is not satisfactory (Kassa and Krejcova 2003). The oxime HI-6, produced and introduced by some countries for the antidotal treatment of severe acute poisonings with soman because of its higher reactivation and therapeutical efficacy compared to currently used oximes such as pralidoxime and obidoxime (Dawson 1994, Kassa and Cabal 1999a), was demonstrated to be significantly less efficacious in eliminating tabun-induced acute neurotoxicity than obidoxime (Kassa and Krejcova 2003). The unsatisfactory efficacy of the above mentioned oximes in eliminating tabun-induced acute neurotoxicity can be explained by the very low potency of these oximes in reactivating tabuninhibited AChE in vitro as well as in vivo (Jokanovic et al. 1996, Puu et al. 1986, Worek et al. 1998). The reason for their weak reactivation potency seems to be the presence of a free electron pair located on amidic nitrogen that makes the nucleophilic attack of oximes very difficult (Eto 1976). Therefore, new oximes have been developed to increase the reactivating potency as well as the neuroprotective efficacy of the antidotal treatment of acute tabun poisonings.

Our results demonstrate that the newly developed oximes (K027, K048) as well as trimedoxime appear to be more effective in eliminating tabun-induced acute neurotoxicity in 
rats than previously tested oximes, although neither are able to completely eliminate tabun-induced signs of neurotoxicity in the case of lethal tabun poisoning. Thus, they seem to be more promising oximes for the antidotal treatment of lethal tabun poisonings than currently used oximes such as pralidoxime, HI-6 and obidoxime (Kassa and Kunesova 2006). Trimedoxime, a relatively weak reactivator of soman-inhibited $\mathrm{AChE}$, is a promising reactivator of tabun-inhibited AChE according to previously published data (Cabal et al. 2004). The reason for its relatively high efficacy is probably the special chemical structure of its molecule. The stereochemical arrangement of oximes can play a role in the difference in the therapeutic efficacy of oximes against tabun (Cabal and Bajgar 1999, Patocka et al., 2005). Both newly developed oximes (K027, K048) also seem to be promising reactivators of tabun-inhibited AChE (Kuca and Kassa 2003, Kuca and Kassa 2004); nevertheless, the difference in reactivating efficacy between the newly developed (K027, K048) and currently available (obidoxime, trimedoxime) oximes is not so high as to think about replacement of the currently used oximes in the treatment of acute tabun poisonings (Kassa et al. 2005, Kassa et al. 2006).

In conclusion, there is no broad spectrum oxime able to satisfactorily counteract the acute toxic effects of all nerve agents. The oxime HI-6 is the most efficacious oxime in reactivating soman or cyclosarin-inhibited $\mathrm{AChE}$ and in protecting soman or cyclosarin-exposed mammals from their acute toxic effects (Kassa and Cabal 1999a,b, Kassa 2002); nevertheless, it is not efficacious enough to protect tabun-exposed animals from tabun-induced neurotoxicity (Kassa and Krejcova 2003). Trimedoxime and the newly developed oximes K027 and K048 are not suitable oximes for the treatment of cyclosarin poisonings because they are not sufficiently effective in reactivating cyclosarininhibited AChE and eliminating cyclosarin-induced toxic effects (Kassa and Cabal 1999b, Kuca and Kassa 2003, Kuca and Kassa 2004). On the other hand, they seem to be the most promising oximes among known oximes for the antidotal treatment of acute tabun poisoning in mammals because of their reactivating and neuroprotective potency (Kassa and Kunesova 2006, Kassa et al. 2005, Kassa et al. 2006).

\section{ACKNOWLEDGEMENTS}

The authors would like to thank to Mrs. E. Reslova and Mrs. J. Uhlirova for their skilful technical assistance and to Mr Vaclav Blaha for the statistical data evaluation. The study was supported by the grant of Ministry of Defence, MO0FVZ0000501.

\section{REFERENCES}

Bajgar J.: The Use of Chemical Weapons and Negotiations on their Ban: from History to the Present Time (in Czech). Nukleus Hradec Kralove, Czech Republic, 2006.

Cabal J., Bajgar J.: Tabun - reappearance 50 years later (in Czech). Chem. Listy, 93:27-31, 1999.

Cabal J., Kuca K., Kassa J.: Specification of the structure of oximes able to reactivate tabuninhibited acetylcholinesterase. Pharmacol. Toxicol. 95:81-86, 2004.

Cassel G., Karlsson L., Waara L. et al.: Pharmacokinetics and effects of HI- 6 in blood and brain of soman-intoxicated rats: A microdialysis study. Eur. J. Pharmacol. 332:43-52, 1997.

Dawson R.M.: Review of oximes available for treatment of nerve agent poisoning. J. Appl. Toxicol. 14:317-331, 1994.

Dohnal V., Kuca K., Jun D.: Prediction of a new broad-spectrum reactivator capable of reactivating acetylcholinesterase inhibited by nerve agents. J Appl. Biomed. 3:139$145,2005$.

Eto M.: Organophosphorus Pesticides: Organic and Biological Chemistry. CRC Press Inc., Cleveland, USA, 1976.

Frantik E., Hornychova M.: Clustering of neurobehavioral measures of toxicity. Homeostasis 36:19-25, 1995.

Hornychova M., Frantik E., Kubat J., Formanek J.: Neurotoxicity profile of supermethrin, a new pyrethroid insecticide. Cent. Eur. J. Publ. Health 3:210-218, 1995.

Jokanovic M.: Anticholinesterase activity and delayed neurotoxic effects of tabun in hens. Vojvosanit. Pregl. 50:451-456, 1993.

Jokanovic M., Maksimovic M., Kilibarda V. et al.: Oxime-induced reactivation of acetycholinesterase inhibited by phosphoramidates. Toxicol. Lett. 85:35-39, 1996.

Kassa J.: Review of oximes in the antidotal treatment of poisoning by organophosphorus nerve agents. J. Toxicol. Clin. Toxicol. 40:803-816, 2002.

Kassa J., Cabal J.: A comparison of the efficacy of a new asymmetric bispyridinium oxime BI-6 with currently available oximes and $\mathrm{H}$ oximes against soman by in vitro and in vivo methods. Toxicology 132:111-118, 1999a.

Kassa J., Cabal J.: A comparison of the efficacy of acetylcholinesterase reactivators against cyclohexyl methylphosphonofluoridate (GF agent) by in vitro and in vivo methods. Pharmacol. Toxicol. 84:41-45, 1999b.

Kassa J., Cabal J., Kuca K.: A comparison of the efficacy of currently available oximes against 
tabun in rats. Biologia 60, Suppl. 17:77-79, 2005.

Kassa J., Koupilova M.: The importance of anticholinergic drug selection for the neuroprotective effects of antidotes in somanpoisoned rats. Homeostasis 12:52-53, 2000.

Kassa J., Krejcova G.: Neuroprotective effects of currently used antidotes in tabun-poisoned rats. Pharmacol. Toxicol. 92:258-264, 2003.

Kassa J., Kuca K., Cabal J., Paar M.: A comparison of the efficacy of new asymmetric bispyridinium oximes (K027, K048) with currently available oximes against tabun by in vivo methods. J. Toxicol. Environ. Health 69, 2006, in press.

Kassa J., Kunesova G.: A comparison of the potency of newly developed oximes (K027, K048) and commonly used oximes (obidoxime, HI-6) to counteract tabuninduced neurotoxicity in rats. J. Appl. Toxicol. 26, published online 21. March 2006.

Kuca K., Bielavsky J., Cabal J., Bielavska M.: Synthesis of a potential reactivator of acetylcholinesterase $1-(4-$ hydroxyiminomethylpyridinium)-3(carbamoylpyridinium)-propane dibromide. Tetrahedron Lett. 44:3123-3125, 2003a.

Kuca K., Bielavsky J., Cabal J., Kassa J.: Synthesis of a new reactivator of tabun inhibited acetylcholinesterase. Bioorg. Med. Chem. Lett. 13:3545-3547, 2003b.

Kuca K., Kassa J.: A comparison of the ability of a new bispyridinium oxime-1-(4hydroxyiminomethylpyridinium)-4-(4carbamoylpyridinium)butane dibromide and currently used oximes to reactivate nerve agent-inhibited rat brain acetylcholinesterase by in vitro methods. J. Enzyme Inhib. Med. Chem. 18:529-535, 2003.

Kuca K., Kassa J.: In vitro reactivation of acetylcholinesterase using the oxime K027. Vet. Hum. Toxicol. 46:15-18, 2004.

Marrs T.C.: Organophosphate poisoning. Pharmacol. Ther. 58:51-66, 1993.
McDonough J.H.Jr., Zoeffel L.D., McMonagle J. et al.: Anticonvulsant treatment of nerve agent seizures: anticholinergics versus diazepam in soman-intoxicated guinea-pigs. Epilepsy Res. 38:1-14, 2000.

Moser V.C., Tilson H., McPhail R.C. et al.: The IPCS collaborative study on neurobehavioral screening methods: II. Protocol design and testing procedures. Neurotoxicology 18:929938, 1997.

Ohtomi S., Takase M., Kumagai F.: Sarin poisoning in Japan. A clinical experience in Japan Self Defense Force (JSDF) Central Hospital. Int. Rev. Arm. Ser. 69:97-102, 1996.

Patocka J., Cabal J., Kuca K., Jun D.: Oxime reactivation of acetylcholinesterase inhibited by toxic phosphorus esters: in vitro kinetics and thermodynamics. J. Appl. Biomed. 3:9199, 2005.

Poziomek E.J., Hackley B.E., Steinberg G.M.: Pyridinium aldoximes. J. Org. Chem., 23:714717,1958

Puu G., Artursson E., Bucht G.: Reactivation of nerve agent inhibited acetylcholinesterase by HI-6 and obidoxime. Biochem. Pharmacol. 35:1505-1510, 1986.

Roth Z., Josifko M., Maly V., Trčka V.: Statistical Methods in Experimental Medicine (in Czech) SZN, Czechoslovakia, 1962.

Sakurada K., Matsubara K., Shimizu K. et al.: Pralidoxime iodide (2-PAM) penetrates across the blood-brain barrier. Neurochem. Res. 28:1401-1407, 2003.

Taylor P.: Anticholinesterase agents. In: J. G. Hardman and L. E. Limbird (eds.): The pharmacological basis of therapeutics, McGraw Hill, NewYork, USA 1996, pp. 161176.

Worek F., Widmann R., Knopff O., Szinicz L.: Reactivating potency of obidoxime, pralidoxime, HI-6 and HLö-7 in human erythrocyte acetylcholinesterase inhibited by highly toxic organophosphorus compounds. Arch. Toxicol. 72:237-243, 1998. 